\title{
Representação social e inclusão: lidando com a diferença
}

\author{
Social Representation and Inclusion: \\ Alternatives to Face Difference at School \\ Representación social y inclusión: \\ como entender la diferencia
}

\author{
ANGEla MARIA B ALTIERI SOUZA \\ Clarilza Prado de Sousa (Db
}

Helenice Maia Gonçalves

\section{Resumo}

O presente artigo procura revelar as representações sociais dos professores na prática da inclusão educacional de alunos com deficiência na escola pública. Trata-se de um projeto que surgiu a partir de necessidades evidenciadas por professores e coordenadores pedagógicos para incluir alunos com deficiência. O objetivo desse projeto é apreender representações sociais de professores sobre a inclusão, bem como refletir e discutir práticas e metodologias dos docentes, o que lhes possibilita repensar sua própria prática e encontrar novos caminhos para inserir alunos com deficiência na escola pública em parceria com a universidade. A pesquisa conta com a participação de professores e alunos do curso de graduação em Psicologia e Pós-Graduação em Educação, bem como docentes da Educação Básica da Rede Pública de Ensino Estadual que aceitaram participar desse estudo, conforme normas éticas. Para tanto, pretende-se investigar as dificuldades de aprendizagem dos alunos incluídos e as dificuldades dos professores da escola para atuar com esses alunos. Foram coletadas as narrativas de professores em dois momentos distintos e estas foram analisadas por meio de metodologia interpretativa como forma de apreender as representações sociais dos professores acerca da prática da inclusão educacional de alunos com deficiência. Os resultados evidenciaram um profundo sentimento de desamparo nas narrativas dos professores e salientaram a necessidade de serem efetivados propostas, medidas e

\footnotetext{
a Pontifícia Universidade Católica de São Paulo (PUC-SP), São Paulo, SP, Brasil. Mestra em Educação, e-mail: angelamariabaltieri@gmail.com

b Pontifícia Universidade Católica de São Paulo (PUC-SP), São Paulo, SP, Brasil. Doutora em Educação, e-mail: clarilza.prado@gmail.com

c Universidade Estácio de Sá (UNESA), Rio de Janeiro, RJ, Brasil. Doutora em Educação Escolar, e-mail: helemaia@uol.com.br
} 
procedimentos que possam aperfeiçoar o processo de atendimento a alunos com deficiência nessa escola, assim como contribuir para a compreensão dos professores sobre as dificuldades específicas de cada um desses alunos.

Palavras-chave: Representação Social. Inclusão na escola pública. Prática docente.

\begin{abstract}
This article will discuss teachers' social representation practicing educational inclusion of students with disabilities in public schools. A project was created through the need for disability students' inclusion, evidenced by teachers and pedagogical coordinators. The goal of this project is to learn about teachers' social representation around disability inclusion, as well as reflect and discuss practical techniques and methodologies of teachers, which would made teachers rethink regarding their own methods and possibilities of creating new approaches in order to embrace students with disabilities in public schools in partnership with the university. This study had the participation of faculty, undergraduate and postgraduated students of Psychology and Education, plus professors of elementary education that works for public schools and accepted to ethically participate in this study. Therefore, it is intended to investigate the difficulties of learning of the included students and also the dilemma that teachers may have to lecture these students. Teachers' narratives were collected in two different moments, these were analyzed through interpretative methodology as a way to understand how social representations of teachers works around educational inclusion of students with disabilities. The result of this study has shown teachers' narratives of a deep feeling of helplessness in and highlights to the need for effective practices, measures and procedures that can be enhanced the process of accomplishing students with disabilities in this school, as well as contributing to the teachers' understanding of each one student's struggle.
\end{abstract}

Keywords: Social Representations. Inclusion in the public schools. Teaching practice.

\title{
Resumen
}

El articulo actual busca revelar representaciones sociales de profesores acerca de inclusión educativa de estudiantes con discapacidad en la escuela publica. Es un proyecto que surgió cuando profesores y coordinadores pedagógicos vieron la necesidad de incluir a estudiantes con discapacidad. El objetivo de este proyecto es aprender representaciones sociales de inclusión, discutir practicas y metodologia de profesores, permitiendo así, la representación de sus mejores prácticas y encontrar nuevos caminhos para la inclusión de estudiantes com discapacidad em la escuela pública em asociación com la universidad; la búsqueda cuenta com la participación de professores de la educación básica de la red pública de educación del estado que aceptaron participar em este estudio. Buscan investigar las dificultades de aprendizaje de los estudiantes y las dificultades de professores de la escuela para que participen em conjunto com los estudiantes. Fueron recolectados narrativas de professores em dos momentos diferentes y fueron analizados con metodologia interpretativa para revelar las representaciones sociales de los professores acerca da practica de inclusión educativo de estudiantes com discapacidad. Los resultados mostraron uma profunda sensación de impotência, em las narrativas de los professores y la necesidad de propuestas, medidas y procedimentos para mejorar el processo de assistência para estudiantes con discapacidad y ayudar en la compreensión de professores acerca de discapacidad específicas de estos estudiantes.

Palabras clave: Representación Social.Inclusión en la escuela pública. Práctica docente. 


\section{Introdução}

Este artigo descreve as possibilidades de, a partir de narrativas de professores, compreender as representações sobre inclusão de alunos com deficiência em salas de aula regulares de escolas do sistema público de educação. Trata-se de um estudo realizado no contexto do Projeto "Desafios da Inclusão", que se desenvolve em uma escola estadual e pretende formar professores para atuarem em seu cotidiano com alunos com diferentes tipos de deficiência.

A inclusão de alunos com deficiência em salas regulares da escola pública é uma determinação legal, uma proposta necessária com a qual concordamos e queremos contribuir para sua viabilização com qualidade. No entanto, faltam informações e principalmente formação de educadores de como lidar com esses alunos na sala de aula ou no ambiente escolar. Sem um laudo específico, sem condições e recursos adequados, muitas escolas contam apenas com o sentimento de solidariedade dos professores e sua intuição sobre como atuar diante das diferentes questões ou dificuldades apresentadas pelos alunos com deficiência. Nesse contexto, temos observado que há alunos com apenas dificuldades de aprendizagem, sem comprometimentos intelectuais, neurológicos ou de qualquer espécie, chamados de "alunos de inclusão" e classificados com uma deficiência que não corresponde às suas reais dificuldades. Constroem-se, assim, legiões de excluídos sob a denominação da inclusão.

Desafiados pelos professores da escola onde se realiza o projeto, que nos descreveram as dificuldades enfrentadas por eles no cotidiano e indicaram a falta de formação que sentiam para atender às necessidades educacionais dos alunos com deficiência, demos início a um programa de atividades que poderiam ser realizadas em conjunto, Universidade e Educação Básica, a fim de construir possibilidades a partir da análise das dificuldades de cada aluno e das necessidades de formação dos professores. Atualmente, o Projeto vem oferecendo formação a esses professores,

\footnotetext{
${ }^{1} \mathrm{O}$ projeto tem a coordenação de Ana Laura Schliemann e conta com a colaboração/participação de professores e alunos de Graduação em Psicologia e Pós-Graduação em Educação, bem como os professores da Rede Pública de Ensino que aceitaram participar da pesquisa.
} 
coordenados pela Professora Ana Laura Schliemann, da Pontifícia Universidade Católica de São Paulo (PUC-SP), por meio de orientações de um programa de formação sobre diferentes deficiências e de práticas docentes, que poderiam beneficiar os alunos e atender às necessidades dos professores.

No contexto desse Projeto, entendemos que poderíamos compreender as representações sociais dos professores acerca da inclusão e de suas práticas pedagógicas, para contribuir com a formação que vem sendo desenvolvida. Passamos, então, a coletar narrativas dos professores, com a devida autorização formal dos docentes envolvidos, durante reuniões, em discussões coletivas e em sala de aula, para que pudéssemos desenvolver processos de análises que nos permitiriam identificar as representações sociais do grupo envolvido para, então, subsidiar o itinerário de formação dos professores que estamos realizando. $\mathrm{O}$ presente texto relata esse processo desenvolvido.

\section{As diretrizes, as conceituações legais da inclusão e as contribuições da Teoria de Representações Sociais (TRS)}

De acordo com a Convenção da $\mathrm{ONU}^{2}$ sobre o direito das pessoas com deficiência, "pessoas com deficiência são aquelas que têm impedimentos de longo prazo de natureza física, mental, intelectual ou sensorial, os quais, em interação com diversas barreiras, podem obstruir sua participação plena e efetiva na sociedade em igualdades de condições com as demais pessoas". A deficiência é conceituada como a repercussão imediata da doença sobre o corpo, impondo uma alteração estrutural ou funcional ao nível tecidual ou orgânico. É um cidadão com os mesmos direitos de autodeterminação e usufruto das oportunidades disponíveis na sociedade.

Pessoas com deficiência (PcD) têm limitação ou incapacidade para o desempenho de determinadas atividades. Podem apresentar uma ou mais deficiências, percebidas ao nascimento ou adquiridas ao longo da vida. Há

\footnotetext{
${ }^{2}$ A Convenção ONU foi instituída em 2008 por meio de aprovação do Decreto Legislativo $\mathrm{n}^{\circ}$ 186, de 9 de julho de 2008, que "aprova o texto da Convenção sobre os Direitos das Pessoas com Deficiência e de seu Protocolo Facultativo, assinados em Nova Iorque, em 30 de março de 2007" (Disponível em: http://www.planalto.gov.br/ccivil_03/Congresso/DLG/DLG-186-2008.htm. Acesso em: 24 maio 2020).
} 
dificuldades que, embora não estejam classificadas como deficiência, podem produzir direta ou indiretamente graus de limitação variados, por exemplo, os distúrbios de fala, da linguagem ou comportamentais e os transtornos orgânicos.

O Censo do Instituto Brasileiro de Geografia e Estatística (IBGE, 1991) apurou a existência de 1,7 milhão de pessoas com deficiência no País, à época, cerca de 1,41\% da população. Uma década depois, o Censo de 2000 (IBGE, 2000) indicou que o percentual seria de $14,5 \%$ dos brasileiros, incluindo na pesquisa as pessoas com mobilidade reduzida. A diferença de 13 pontos percentuais explica-se pela mudança da metodologia da pesquisa, que passou a adotar a Classificação Internacional de Funcionalidade, Deficiência e Saúde (CIF) da Organização Mundial da Saúde (OMS), que define graus de dificuldades para a realização de tarefas pelos indivíduos. Os números do Censo 2000 incluem, portanto, idosos e a população com obesidade, além de indivíduos com alguma limitação física, sensorial ou intelectual.

Em 2010, foi realizado novo Censo Demográfico (IBGE, 2010) que revelou que cerca de 45.606 .048 pessoas $(23,9 \%$ da população brasileira) têm algum tipo de deficiência. Segundo esse censo, mais de 13 milhões de pessoas apresentam deficiência motora, o que corresponde a $6,95 \%$ da população do país. A deficiência física é mais significativa no sexo feminino, afetando $61,5 \%$ das mulheres, o que representa 8 milhões dessa população. Quanto ao sexo masculino, a prevalência descrita fica em 38,5\%, o que totaliza 5 milhões de homens. A Tabela 1 mostra a quantidade e o percentual de brasileiros de acordo com a funcionalidade declarada por eles.

Tabela 1 - Brasil: População segundo funcionalidade declarada (2010)

\begin{tabular}{l|l|l}
\hline Descrição & Quantidade de pessoas (em milhares) & \% \\
\hline Pessoa com deficiência (PcD) & 12.748 .663 & 6,7 \\
\hline Pessoa com limitação funcional (PLF) & 32.857 .385 & 17,2 \\
\hline $\begin{array}{l}\text { Pessoa sem deficiência e sem limitação } \\
\text { funcional (PSDLF) }\end{array}$ & 145.084 .976 & 76,1 \\
\hline Total & 190.691 .024 & 100 \\
\hline
\end{tabular}

Fonte: IBGE (2010). 
Deficiência é, ainda, um conceito em construção, ora relacionada a variações do modelo médico, ora do modelo social, o que evidencia a necessidade de aprofundar estudos nessa área, a fim de que cada vez mais se conheçam aspectos do fenômeno e que, portanto, possa ser oferecido um atendimento mais amplo às PcD. Nesse contexto, compreende-se a dificuldade do processo de inclusão, uma vez que este depende de uma série de situações e colocações que não podem ser resolvidas apenas pela legislação, mas requer orientações específicas e condições a serem oferecidas às escolas.

A inclusão define-se como o ato de incluir e estar compreendido, ou seja, inserir, introduzir e fazer parte (FERREIRA, 2008) de grupos e núcleos dos quais antes os sujeitos não faziam parte. Um processo complexo que emerge da promoção de direitos e acesso a escolhas, que necessitam de adequação dos "sistemas sociais gerais da sociedade de tal modo que sejam eliminados os fatores que excluam" (SASSAKI, 1999, p. 21).

A inclusão da PcD na sociedade foi proposta com a perspectiva de melhorar sua qualidade de vida e, para tanto, algumas medidas foram colocadas em pauta; entre elas destaca-se a educação inclusiva de crianças e jovens e cotas para deficientes em empresas como medida para auxiliar a empregabilidade. Há também grande quantitativo de propostas que buscam a inclusão da $\mathrm{PcD}$ no mundo do trabalho, porém grande parte do sucesso da inclusão depende da possibilidade de a PcD ter tido uma formação escolar que lhe permita relacionar-se com outros grupos e ter desenvolvido habilidades que lhes possibilitam atuar para além de seu universo familiar.

No contexto educacional brasileiro, a partir a Conferência Mundial sobre Necessidades de Educação Especial, realizada em 1994 na cidade de Salamanca, Espanha (BRASIL, 1994), impulsionou-se o debate em prol de práticas inclusivas. No decorrer da década de 1990, a partir da discussão de vários educadores brasileiros, a educação passa a ser um direito de todos. Nas palavras de Freire (1991, p. 126):

Você, eu, um sem-número de educadores sabemos todos que a educação não é a chave das transformações do mundo, mas sabemos também que as mudanças do mundo são um quefazer 
educativo em si mesmas. Sabemos que a educação não pode tudo, mas pode alguma coisa. Sua força reside exatamente na sua fraqueza. Cabe a nós pôr sua força a serviço de nossos sonhos.

O autor analisa o papel da educação, o papel do educador como sujeito e do ato de educar que está presente continuamente no processo educativo. Na sociedade contemporânea, os debates acerca da inclusão social de PcD vêm aumentando, no sentido de possibilitar maior participação social dessas pessoas.

As narrativas e práticas de professores de/com alunos com deficiências é um processo complexo. A TRS, a partir de postulações de Serge Moscovici, contribui para o desvelamento dos significados e sentidos presentes nessas narrativas. Primeiramente, é preciso entender que a perspectiva psicossocial da TRS estabelece que as narrativas dos sujeitos precisam levar em conta o contexto em que esses sujeitos estão inseridos, para compreender quais, como e por que estão sendo construídas tais representações sociais, e ainda que tipo de realidade social estão produzindo.

\section{Breve panorama da pesquisa narrativa no contexto brasileiro}

A origem da autobiografia se deve ao gênero biográfico que, por sua vez, descende da historiografia do século XIX, uma forma de fazer história que enaltecia o biografado e sua trajetória de vida. Considerado um gênero menor e por muito tempo deixado de lado, a partir dos anos 1980 o interesse pelos estudos biográficos tornou a crescer e estes se voltaram para as relações entre indivíduo e sociedade, para a recuperação da dimensão subjetiva dos processos sociais e para a análise do contexto onde os sujeitos se encontram. Schmidt (1996) considera que o livro de Carlo Ginzburg, O queijo e os vermes, pode ser identificado como um representante desse turning point, pois nele o autor apresenta um estudo biográfico sobre a cultura camponesa na Europa pré-industrial que sofria a influência da cultura da elite, questionando-se sobre que relevância teriam as ideias e crenças de um indivíduo em relação às de seu grupo social, ou seja, a biografia é pensada para além da individualidade. A partir dessas considerações, Schmidt (1996) propõe a construção 
de uma biografia pela perspectiva da vida cotidiana, que se refere à vida de todos os dias, aos gestos, ritos e ritmos repetidos diariamente, abrangendo a vida familiar, o trabalho o lazer, entre outros aspectos, que têm hierarquia interna, social e historicamente determinada. Sua proposta de articular o cotidiano e a história de vida permite lançar um novo olhar para os sujeitos, sua subjetividade, seus contextos e suas relações com o outro, pois o cotidiano é um espaço de interações concretas, um mundo de vida, como define Schutz (1987).

A partir dos anos 1990, o interesse pelas trajetórias individuais é intensificado, pois a ideia de um sujeito ativo e pensante e seu vínculo social retorna ao centro da cena, implicando "uma outra escala de análise, mais próxima dos atores sociais" (JODELET, 2009, p. 688). Três gêneros distintos, biografias, histórias de vida e autobiografias, que tomam a sequência da vida individual, ressurgem como metodologia de excelência em pesquisas nas Ciências Humanas e Sociais, porém diferem quanto à forma como a trajetória de vida é elaborada e apresentada. $\mathrm{Na}$ autobiografia, o próprio narrador seleciona e constrói o texto; na história de vida é um narrador que fala sobre sua existência ao longo do tempo; na biografia é a história de uma pessoa redigida por outra. As diferenças entre os gêneros, entretanto, dependem da visão dos autores que com elas trabalham. Queiroz (1988, p. 25), por exemplo, considera que é uma autobiografia quando o relato é da própria pessoa e neste se busca "como estão ali operando as relações do indivíduo com seu grupo, com sua sociedade", sendo necessário, portanto, conhecer as condições de sua produção e o quadro social de sua constituição (PEREIRA, 2000).

No Brasil, desde os anos 1980 o método autobiográfico vem ganhando evidência, mas é nos anos 1990 que eclode o reconhecimento das pesquisas com as histórias dos sujeitos comuns e as histórias de vida (ALVES-MAZZOTTI, 2015). $\mathrm{Na}$ década seguinte,

[...] os desafios permanecem relativamente os mesmos na tarefa de explorar os referenciais epistemológicos, teóricos e metodológicos do (auto)biográfico em suas grandes vertentes: como fenômeno antropológico, método de pesquisa, dispositivo de pesquisa-formação e, modos de (auto)biografização da vida, mediante os mais variados instrumentos semióticos, com vistas a ampliar as interfaces entre a Educação e as demais ciências que investigam o humano em suas relações com o mundo físico e o sensível (PASSEGGI; SOUZA, 2016, p. 23). 
Ao longo do levantamento de pesquisas narrativas no campo científico, destacam-se inúmeras contribuições de autores como Steban (2010), Louro (1991), Haguette (2013) e Queiroz (1988), que discorrem sobre a desvalorização dessas pesquisas no período do pós-guerra e sua revalorização como uma metodologia capaz de apreender os fenômenos sociais, dando condições para seu dinamismo intrínseco e fornecendo ao pesquisador detalhes e profundidade suficientes para a compreensão da complexidade dos problemas educacionais. Desde 2004, acontecem edições do Congresso Internacional de Pesquisa Autobiográfica (CIPA), concentrando debates teórico-metodológicos entre os pesquisadores dessa abordagem situada na pesquisa qualitativa.

Resgatar a importância dos relatos orais é, segundo Queiroz (1988), fundamental para a obtenção e conservação do saber, ao dizer respeito tanto ao passado longínquo quanto ao mais próximo e também às experiências diretas ou àquelas transmitidas entre as gerações de um determinado grupo social. Como o autor explica, um conhecimento que é construído e cristalizado foi, antes, um conhecimento relatado, transmitido oralmente por indivíduos e grupos. "Da mesma forma que desenho e palavra escrita constituem uma reinterpretação do relato oral, também o indivíduo intermediário, por mais fiel, acrescenta a sua própria interpretação àquilo que está narrando" (QUEIROZ, 1988, p. 17).

Um dos principais desafios para o uso de narrativas autobiográficas nas pesquisas educacionais no Brasil, conforme Passeggi e Souza (2016), é o reconhecimento da relevância das investigações científicas pelo mundo científico. Os autores identificam que essa ideia é motivada pela dificuldade de categorização dos estudos centrados em histórias de vida, uma vez que fogem à lógica dos esquemas positivistas com a focalização de normas e leis gerais do comportamento humano, pois voltam-se à valorização da experiência dos sujeitos humanos que se modificam, se reconstroem, são variados e plurais.

A biografização, como pontua Alheit (2011, p. 37, grifo do autor), é o

"lado interior" daquilo que Ulrich Beck ou Anthony Giddens descreveram como individualização. [...] um código pessoal com o qual nos apoderamos de novas experiências. Cada processo de aprendizagem atual funciona exatamente assim, e por isso toda a aprendizagem é, em certo sentido, "aprendizagem biográfica". 
Em casos de percursos formativos com a biografização, Passeggi (2011, p. 148) revela que "uma prática com grupos reflexivos pode propiciar partilha, reflexão e ressignificação das 'experiências com o outro"'. Nesse sentido, Passeggi e Souza (2016) exprimem que nós nos construímos como sujeitos num processo permanente de biografização (atividade mental e comportamental de experiência e da ação). Um entrelaçamento entre "razão e emoção, sujeito e objeto de reflexão, nos processos de interpretação da experiência" e de "atribuição de sentido à vida" das pessoas comuns, que trazem à tona a subjetividade e a experiência de homens comuns (PASSEGGI; SOUZA, 2016, p. 11-14; 16).

O processo de biografização pode tanto contribuir para a compreensão do pesquisador com relação à experiência do pesquisado quanto para evidenciar o relato, assim como a experiência do pesquisador. Bosi (2012, p. 38) afirma que a compreensão é de que os pesquisadores são, simultaneamente, sujeitos e objetos de suas pesquisas, isto é, “sujeito enquanto indagávamos, procurávamos saber. Objeto quando ouvíamos, registrávamos, sendo como que um instrumento de receber e transmitir a memória de alguém, um meio de que esse alguém se valia para transmitir suas lembranças", possibilitando ao pesquisador, por meio de narrativas, reconstruir "tensões implícitas", "reconstituir comportamentos e sensibilidades de uma época" (BOSI, 2013, p. 16).

A autobiografia vem sendo utilizada em pesquisas educacionais como uma estratégia para o avanço à subjetividade, uma vez que falar de si envolve um processo de expressão da experiência (DELORY-MOMBERGER, 2008; JOSSO, 2004; 2012; PINEAU, 2006). "Ela fornece um modelo tangível do modo como nossa consciência trabalha o material da vida, díspar, heterogêneo, fragmentado, para constituí-lo em um conjunto dotado de unidade e coerência" (DELORY-MOMBERGER, 2008, p. 58).

Passeggi (2010) afirma que os estudos autobiográficos integram os elementos do pensamento, da linguagem e da práxis social como meio de interpretação das representações e sentidos que os sujeitos atribuem aos itinerários de vida e da formação, ou seja, a linguagem desempenha o papel de interação entre os sujeitos, 
logo, a palavra é instrumento de expressão social e compreensão de si. Para tanto, o ato de narrar pode permear uma reflexão sobre si, o que possibilitaria ao sujeito "dar sentido às experiências e, nesse percurso, constrói outra representação de si: reinventa-se" (PASSEGGI, 2011, p. 148).

Ao indicar que foi o narrador que, "por motivos estritamente pessoais, resolveu narrar sua existência, [foi ele próprio que] deu-lhes o encaminhamento que melhor lhe pareceu" (QUEIROZ, 1988, p. 23). O narrar, segundo Passeggi (2015), valoriza a capacidade de reflexão das pessoas e, como diz Delory-Momberger (2008, p. 58-59),

[...] a compreensão que desenvolvo da narrativa de alguém inscreve-se num jogo de interrelações que faz dessa narrativa não um objeto unânime e identicamente decodificável, mas algo que está em jogo entre alguém e mim, e entre mim e mim mesmo. Somente posso (re)construir o mundo de vida da narrativa que ouço ou leio, relacionando esse mundo com os meus próprios constructos biográficos e compreendendo-o nas relações de ressonância e de inteligibilidade com minha própria experiência biográfica.

Apreender as representações sociais por meio de narrativas subjaz um processo pelo qual o sujeito singular "alcança sua própria forma, constitui sua própria identidade, configura sua particular humanidade, ou, definitivamente, converte-se no que é” (BONDÍA, 2002a, p. 45).

\section{Estudo de narrativas como meio de investigar as representações sociais: autobiografia, identidade e reconhecimento social}

As pesquisas voltadas às trajetórias dos professores, às experiências que vivenciaram durante seu desenvolvimento profissional, a sua autobiografia, têm revelado como representam seu trabalho, tanto na esfera subjetiva quanto na intersubjetiva e transubjetiva (JODELET, 2009), por meio de diversos assuntos que permeiam o campo da Educação e que são arrolados por eles quando narram suas histórias. Passeggi, Souza e Vicentini (2011, p. 371) consideram que o processo de biografização possibilita "estudar como os indivíduos dão forma às suas experiências e sentido ao que antes não tinha, como constroem a consciência 
histórica de si e de suas aprendizagens nos territórios que habitam e são por eles habitados".

Sob o olhar psicossocial da TRS, compreende-se o sujeito como um ser humano que constrói sua realidade e é construído por ela na cotidianidade. Moscovici (1978, p. 28) sustenta que a representação social é um “corpus organizado de conhecimentos e uma das atividades psíquicas graças às quais os homens tornam inteligível a realidade física e social, inserem-se num grupo ou numa ligação cotidiana de trocas, e liberam os poderes de sua imaginação”. Mais especificamente, "é uma forma de conhecimento socialmente elaborada e partilhada, com um objetivo prático, e que contribui para a construção de uma realidade comum a um conjunto social” (JODELET, 2001, p. 22).

A aproximação entre a abordagem autobiográfica e a abordagem psicossocial moscoviciana é considerada possível por meio das narrativas de vida, como propõe, por exemplo, Alves-Mazzotti (2015, p. 83) ao enfatizar que a primeira propicia investigações sobre docência, formação e vida dos professores "apontando um movimento mais subjetivo e humanizado de pesquisar a profissão docente", além de permitir "apreender e discutir questões sobre percursos formativos, condições do trabalho docente e cotidiano escolar"; e a segunda porque se volta à relação entre representações sociais e condutas, definida como central na teoria das representações sociais.

Em suas narrativas, os sujeitos pensam e refletem a respeito de suas experiências, sobre um já vivido, pois é um ser pensante e que age. É a reabilitação da experiência dos sujeitos, considerados em sua singularidade e sublimando a importância do contexto particular que dá sentido à experiência (JODELET, 2009). "O sujeito da experiência seria algo como um território de passagem, algo como uma superfície sensível que aquilo que acontece o afeta de algum modo, produz alguns afetos, inscreve algumas marcas, deixa alguns vestígios, alguns efeitos" (BONDÍA, 2002b, p. 24). O campo da experiência permeia dimensões individual e coletiva da memória e estas são interdependentes. Halbwachs (2012, p. 33) traz à lembrança "como nós e as testemunhas fazíamos parte de um mesmo grupo e pensávamos em comum com relação a certos aspectos, permanecemos em contato 
com esse grupo e ainda somos capazes de nos identificar com ele e de confundir nosso passado com o dele". A memória se dá em meio a um processo de coesão social, tendo em vista o pertencimento e a adesão afetiva dos sujeitos aos grupos. Nesse sentido, há um reconhecimento mútuo entre o sujeito e os Outros "eu" e "nós"; eles afetam-se mutuamente e coexistem (esfera pública e particular das instituições) intersubjetivamente (MARKOVÁ, 2017).

Ao articular relatos orais e representações sociais, Rigotto (1998, p. 124) refere-se às experiências pregressas que podem indicar posturas diversas, que "transitam num leque que vai desde a negação do problema até a assunção de si enquanto sujeito no processo coletivo de transformação da realidade". Portanto, o processo de apreensão de representações sociais por meio de narrativas pode possibilitar ao sujeito passar por um processo de construção da experiência vivida e desnaturalizar a diferença.

Honneth (2011) acrescenta a essa discussão da construção do sujeito a questão da intencionalidade e da intersubjetividade na relação com o outro, orientada pela luta pelo reconhecimento. Para o autor, a luta pelo reconhecimento pode alterar os padrões sociais e construir subjetividades sociais. Esse processo dialógico, para Honneth, a luta por reconhecimento, envolve tanto a consciência de si quanto a consciência de outros e perpassa por três domínios: amor, direitos e estima social (MENDONÇA, 2009).

Para Braga e Schumacher (2013, p. 379), pessoas com deficiência podem ser consideradas um grupo, uma categoria social,

[...] o que as faz pertencerem a um grupo não é propriamente o fato de possuírem uma característica física, uma diferença em relação às pessoas ditas normais, o que denominamos deficiência. O que faz das pessoas com deficiência um grupo que podemos tratar como categoria de análise é a experiência comum.

Em nosso estudo procuramos analisar a partir das narrativas de professores as representações sociais de professores sobre essa categoria: alunos de inclusão, alunos com deficiência. Compreender os limites e as possibilidades dessa luta por reconhecimento desse grupo social, cuja experiência os torna uma categoria sem 
vOz, sem condições de autorrealização pessoal, que muitas vezes necessitaria que o reconhecimento fosse feito por outros, que não são eles.

\section{O estudo realizado}

A escola onde estamos desenvolvendo o estudo aqui relatado está localizada em uma região periférica e com alto grau de vulnerabilidade social e atende alunos do Ensino Fundamental e Médio com e sem deficiência. Para tanto, a escola dispõe de uma sala de atendimento educacional especializado (AEE) ${ }^{3}$ e de apenas um professor que atende alunos com Transtorno do Espectro Autista (TEA) matriculados na escola e de outras da região. Esse atendimento é realizado semanalmente, em horários específicos previamente agendados com os pais e o professor, que desenvolve atividades diversificadas, planejadas para cada aluno. O professor trabalha, por exemplo, com atividades teatrais, jogos, entre outras. Entretanto, alunos com outros tipos de deficiência precisam se locomover até outros locais que tenham AEE para sua deficiência.

Importante relatar que a escola não possui dependências acessíveis aos alunos com deficiência (rampas e sanitários acessíveis) e tecnologias assistivas recomendadas.

A coleta de dados foi realizada em 2019, durante observação em classe, quando a questão da inclusão foi vivenciada pelos professores, em reunião de colegiado de professores e em discussão formalmente organizada para discussão da temática da inclusão com a presença de 19 professores que atuam na escola em que se procurou analisar a problemática, identificar os alunos e principalmente escalonar os problemas a serem considerados pela escola.

A discussão em grupo foi orientada pela proposta de Weller (2006, p. 246), que a considera "uma ferramenta importante para a reconstrução dos contextos sociais e dos modelos que orientam as ações dos sujeitos", cujo "objetivo principal é a análise dos epifenômenos (subproduto ocasional de outro) relacionados ao meio

\footnotetext{
${ }^{3}$ Atendimento Educacional Especializado - AEE (regulamentação de acordo com a SE/SP n. ${ }^{\circ}$ 68, de 12.12.2017).
} 
social, ao contexto geracional, às experiências de exclusão social, entre outros" (WELLER, 2006, p. 247). Foram adotados os princípios de Bohnsack, como sugere a pesquisadora, para a condução da discussão: estabelecimento da relação de confiança mútua; perguntas dirigidas ao grupo como um todo e que estimulassem a participação e a interação do grupo; e formulação de perguntas que gerassem narrativas, e não apenas a descrição de fatos. Em um segundo momento, ainda seguindo a orientação da autora, procuramos aprofundar e esclarecer aspectos que surgiram no primeiro momento e, num terceiro momento, checar informações, lançar perguntas mais provocativas e divergentes que permitiram identificar conflitos, divergências e concordâncias e também colocar em discussão aspectos que despertaram dúvidas para que fossem esclarecidos ou ratificados.

Utilizando uma metodologia qualitativa e interpretativa proposta por Denzin e Lincoln (2000), pudemos analisar as narrativas ${ }^{4}$, as descrições obtidas nas interações face a face, que descreviam a natureza da comunicação que se construía na comunidade escolar sobre inclusão de alunos em classes regulares.

As narrativas viabilizam apreender o que as pessoas lembram, evidenciando “a experiência” (JOVCHELOVITCH; BAUER, 2002, p. 91). Trata-se de uma forma de reconstituir "tensões implícitas", "subentendidos" ou não ditos "por medo" (BOSI, 2013, p. 16), o que possibilita uma compreensão detalhada das "crenças, atitudes, valores e motivações em relação ao comportamento" (GASKELL, 2002, p. 65).

Moscovici (2015, p. 21) define representações sociais como:

Um sistema de valores, ideias, práticas, com uma dupla função: primeiro estabelecer uma ordem que possibilitará às pessoas orientar-se em seu mundo material e social e controlá-lo; e, em segundo lugar, possibilitar que a comunicação seja possível entre os membros de uma comunidade, fornecendo-lhes um código para nomear e classificar, sem ambiguidade, os vários aspectos de seu mundo e da sua história individual e social.

Portanto, ao considerarmos as representações sociais, focalizamos como as pessoas enfrentam a vida real cotidiana, o que nos possibilita conhecer informações,

\footnotetext{
${ }^{4}$ Os dados coletados no grupo de discussão observaram os aspectos legais no que se refere ao anonimato dos participantes da pesquisa informado ao assinarem o termo de consentimento livre e esclarecido (TCLE).
} 
opiniões, crenças e valores com os quais os sujeitos estabelecem relações, assim como no tocante ao sujeito e ao grupo (MOSCOVICI, 2015). Logo, a abordagem das narrativas permitiu evidenciar as experiências, as representações sociais e as subjetividades do grupo de professores.

\section{Discussão das narrativas e a busca por representações sociais de professores sobre a inclusão de alunos com deficiência em classes regulares}

As análises das narrativas foram realizadas em duas etapas:

- agrupamento de significados identificados nas narrativas dos sujeitos;

- categorização das narrativas em núcleos de sentido que agrupavam significados identificados nas narrativas que apresentavam a mesma orientação simbólica.

Esse processo de análise das narrativas permitiu compreender as características das representações sociais dos professores sobre inclusão. Nesse sentido, a análise dos agrupamentos de significados formados possibilitou identificar as seguintes categorias de sentido:

- a qualificação formativa que os professores precisariam ter;

- a experiência da relação construída em sala de aula com o aluno deficiente;

- a escola, o governo, as condições de trabalho.

Quanto à primeira categoria de sentido, a qualificação formativa que os professores precisariam ter, a análise das narrativas dos professores categorizadas nesse item indica que para os professores a qualificação para atuar com alunos com deficiência deveria ser dada já na formação inicial, quando realizam na Faculdade os cursos de Magistério (Pedagogia e Licenciaturas).

Os professores evidenciam que "[...] A formação do professor na Faculdade também não trata desse assunto”. Indicam a falta de um ponto de partida que lhes permita iniciar sua atuação, que não conseguem reconhecer: “[...] tem que saber 
como começar quando se trabalha com alunos deficientes" e "[...] só por curiosidade de pesquisa que o professor vai atrás".

A demonstração de insegurança desses professores ao relatarem suas dificuldades fica evidente em suas narrativas. Acreditam que uma formação quase de especialista os tornaria capazes de solucionar todas as dificuldades que sentem em sala de aula.

No tocante à segunda categoria, a experiência da relação construída em sala de aula com o aluno deficiente, "eu vou tentando [...]", fazem inúmeras tentativas, mas gostariam de ir além. Essa categoria reuniu as narrativas de professores que relatam sobre suas experiências em sala de aula para superar as dificuldades de formação, de apoio institucional. Relatam os professores:

[...] Como não existe laudo, a gente fica procurando, observando.

[...] Tem que se saber como começar de onde começar com esses alunos.

Tenho visto que têm alunos que não assimilam o alfabeto, mas depois que atuei mais firme ele começou a acertar algumas letras.

É na sala de aula que vão construindo seus diagnósticos, suas hipóteses de atuação.

Ele fugia, dispersava facilmente, no ditado ele punha qualquer letra. Hoje acho que tem déficit de atenção.

Antes eu achava que não conseguia alfabetizar.

$\mathrm{Na}$ internet tem alguns materiais diferenciados, eu fico sempre procurando. Mas a escola não tem áudio, não tem material.

Eu comprei material para trabalhar em classe. Mas só eu não dá.

Observou-se, nas narrativas, que esse esforço dos professores é claro. Quando afirmam ...eu vou tentando, indicam desde compra de materiais, pesquisas que realizam, cursos que procuram fazer, até estratégia simples de atuação.

Para um dos professores, esse esforço também deveria servir de ensinamento aos outros alunos, para que aprendessem a lidar com o aluno deficiente.

Demorei um ano para fazer o aluno falar "oi" para mim. Pensei que ele não falava. Quando ele começou a falar, perguntei aos demais alunos se eles sabiam que ele falava. Perguntei se cumprimentavam o colega.

No contexto dessas dificuldades, observamos experiências humanas incríveis como a do professor que descreve sua atuação com um aluno com múltiplas deficiências, “[...] ele tinha paralisia, autismo, retardo intelectual, dificuldade de fala, superagitação", e ele só conseguiu dar aula se ficasse abraçado ao aluno durante a 
aula. Também o professor que relata que ficou dois anos tentando fazer o aluno compreender algumas ordens. Finalmente havia conseguido.

Esse "tentando...", observado na prática e nas falas do professor, indica, por um lado, a força de quem não desiste, mas que também, de outro lado, propicia a construção de um contexto nem sempre adequado às necessidades desses alunos.

As análises evidenciam que os professores constroem representações que lhes possibilitam entender as tristezas e as dificuldades que sentem em sala de aula, quando, por exemplo, afirmam:

Vem de famílias desestruturadas. Tratar de deficiência não deveria ser só responsabilidade do professor na escola. E a família? Não sei mais como atuar. Há momentos insuportáveis.

Já na terceira categoria, a escola, o governo, as condições de trabalho, os professores indicam em suas narrativas que os governos, em vários mandatos, deixaram a questão da inclusão por conta da escola e, mais especificamente, para os professores que isoladamente têm que resolver a questão. Nem mesmo a família se responsabiliza pela questão da inclusão de seus filhos.

O governo tem que valorizar o povo.

O governo tem que olhar a criança e a escola.

A escola deixou de ser um lugar seguro.

Os pais entregam os filhos no portão e não informam nada.

Os alunos não têm laudo.

As escolas não têm recursos para lidarem com os alunos. Tudo fica por conta dos professores.

Os professores revelam, em suas descrições sobre a escola, a total falta de recursos em que estas se encontram há muito tempo, desde que foi implantada a inclusão e poucas medidas foram tomadas. A escola deveria ter condições integrais, para família, com equipe médica, serviço social etc.

\section{Considerações finais}

O estudo revelou que os professores evidenciam em suas narrativas uma representação social de desamparo relativamente à inclusão dos alunos com deficiência. Desamparados pelos governos, sem que a escola tenha como apoiá-los 
(ela mesmo desamparada nessa questão), sentem-se sem nenhuma condição de atuação, na perspectiva de lutar sozinhos pelo reconhecimento da inclusão — uma luta que lhes é atribuída, mas cujas possibilidades lhes são todas retiradas. Sentem-se em um conflito. Por um lado, mostram-se incapazes de vencer essa luta, estão em total desamparo, mas, de outro, o contato direto com os alunos impede-os de abandonar o campo de batalha. Culpam os pais, mas reconhecem que estes também estão desamparados em sua luta. Sabem que a escola poderia fazer alguma coisa, mas igualmente ela foi abandonada pelos governos, uma vez que destacaram como grandes desafios enfrentados a desvalorização da profissão docente, a falta de estrutura física e material, a quantidade de alunos por sala e a falta de apoio por parte do "governo".

Nossos estudos têm mostrado que esses professores, mesmo em todas essas circunstâncias, não abandonam a luta e com todas as dificuldades esperam por dois anos para que um aluno aprenda um gesto, alegram-se depois de um ano quando um aluno com deficiência responde ao seu cumprimento. No entanto, eles também sabem que poderiam ir além... se a escola tivesse condições.

É interessante ressaltar que, apesar de a educação ser um direito fundamental, expresso no art. $6^{\circ}$ da Constituição Federal — um direito social —, os alunos com deficiência tornam-se invisíveis aos Outros. Nessa linha, Fraser (2006) mostra que os princípios normativos podem conter "limitações morais subjacentes à integração social", uma vez que a "justiça" ou o "bem-estar" devem "ser proporcionais à sua capacidade de assegurar as condições de reconhecimento mútuo em que a formação da identidade pessoal é primordial" (FRASER, 2006, p. 18; 136).

Nesse sentido, evidencia-se que o aluno com deficiência não é reconhecido como um cidadão de direitos realmente efetivados na prática escolar, com direito a receber uma educação que atenda a suas especificidades. Atribuir unicamente ao professor toda a responsabilidade de educação, sem apoio específico da escola, das secretarias de educação, dos governos, significa, em última instância, uma negação de direitos.

Finalmente, queremos enfatizar que tal contexto possível de ser analisado a partir de narrativas de professores em sua prática e suas descrições em grupos de 
discussão está possibilitando a construção de representações de professores, marcadas pelo "desamparo." Nesse sentido, o pensamento "considerado como um ambiente (como atmosfera social e cultural)" (MOSCOVICI, 2015, p. 33) que se constitui na escola, pelas representações sociais de professores sobre inclusão, revela uma realidade marcada pela falta de direitos, condições e possibilidades ao aluno com deficiência, mas que também atinge a subjetividade social dos professores, que se veem desamparados numa luta sem reconhecimento.

\section{Referências}

ALHEIT, P. "Biografização" como competência-chave na modernidade. Revista da FAEEBA - Educaşão e Contemporaneidade, Salvador, v. 20, n. 36, p. 31-41, jul./dez. 2011.

ALVES-MAZZOTTI, A.-J. Histórias de vida de professores, formação e representações sociais: uma proposta de articulação. Revista de Educação Pública, Cuiabá. v. 24, n. 55, p. 81-101, jan./abr. 2015.

BONDÍA, J. L. Nietzssche \& a educação. Belo Horizonte: Autêntica, 2002a.

BONDÍA, J. L. Notas sobre a experiência e o e o saber de experiência. Revista Brasileira de Educação, Rio de Janeiro, n. 19, p. 20-28, jan./abr. 2002b.

BOSI, E. Memória e sociedade: lembrança de velhos. 17. ed. São Paulo: Companhia das Letras, 2012.

BOSI, E. O tempo vivo da memória: ensaios de psicologia social. 3. ed. São Paulo: Ateliê Editorial, 2013.

BRAGA, M. M. S.; SCHUMACHER, A. A. Direito e inclusão da pessoa orientada pela Teoria do Reconhecimento Social de Axel Honneth. Revista Sociedade e Estado, v. 28, n. 2, p. 375-392, maio/ago. 2013.

BRASIL. Declaração de Salamanca e Linha de Ação sobre Necessidades Educativas Especiais. Brasília: Coordenadoria Nacional para Integração da Pessoa Portadora de Deficiência, 1994.

BRASIL. Decreto Legislativo no 186 , de 9 de julho de 2008. Aprova o texto da Convenção sobre os Direitos das Pessoas com Deficiência e de seu Protocolo Facultativo, assinados em Nova Iorque, em 30 de março de 2007. Diário Oficial da União, Brasília, 10 jul. 2008.

DELORY-MOMBERGER, C. Biografia e educação: figuras do indivíduo-projeto. São Paulo: Paulus; Natal: EDUFRN, 2008.

DENZIN, N. K.; LINCOLN, Y. S. The discipline and practice of qualitative research. In: DENZIN, N. K.; LINCOLN, Y. S. Handbook of Qualitative Research. Thousand Oaks: Sage, 2000. p. 1-36. 
FERREIRA, A. B. H. Dicionário Aurélio da língua portuguesa. 7. ed. Curitiba: Positivo, 2008.

FRASER, N. Uma deformación que hace imposible el reconocimiento: réplica a Axel Honneth. In: FRASER, N; HONNETH, A. ¿Redistribución o reconocimiento?: un debate político-filosófico. Madrid: Morata, 2006. p. 17-88.

FREIRE, P. A educação na cidade. São Paulo: Cortez, 1991.

GASKELL, G. Entrevistas individuais e grupais. In: BAUER, M. W.; GASKELL, G. Pesquisa qualitativa com texto, imagem e som: um manual prático. Petrópolis: Vozes, 2002. p. 64-89.

HAGUETTE, T. M. F. A história de vida. In: HAGUETTE, T. M. F. Metodologias qualitativas na sociologia. Petrópolis: Vozes, 2013. p. 74-80.

HALBWACHS, M. A memória coletiva. São Paulo: Centauro, 2012.

HONNETH, A. Luta por reconbecimento. Para uma gramática moral dos conflitos sociais. São Paulo: Editora 34, 2011.

INSTITUTO BRASILEIRO DE GEOGRAFIA E ESTATÍSTICA (IBGE). Censo Demográfico, 1991. Disponível em: https://biblioteca.ibge.gov.br/bibliotecacatalogo?id=782\&view=detalhes. Acesso em: 12 fev. 2020.

INSTITUTO BRASILEIRO DE GEOGRAFIA E ESTATÍSTICA (IBGE). Censo Demográfico, 2000. Disponível em: https://www.ibge.gov.br/censo/numeros.shtm. Acesso em: 12 fev. 2020.

INSTITUTO BRASILEIRO DE GEOGRAFIA E ESTATÍSTICA (IBGE). Censo Demográfico, 2010. Disponível em: https://censo2010.ibge.gov.br/. Acesso em: 12 fev. 2020.

JODELET, D. Representações sociais: um domínio em expansão. In: JODELET, D. (org.). As representações sociais. Rio de Janeiro: EDUERJ, 2001. p. 17-44.

JODELET, D. O movimento de retorno ao sujeito e a abordagem das representações sociais. Sociedade e Estado, Brasília, v. 24, n. 3, p. 679-712, set./dez. 2009.

JOSSO, M. C. Experiências de vida e formação. São Paulo: Cortez, 2004.

JOSSO, M. C. O corpo biográfico: corpo falado e corpo que fala. Educação e Realidade, Porto Alegre, v. 37, n. 1, p. 19-31, jan./abr. 2012.

JOVCHELOVITCH, S.; BAUER, M. W. Entrevista narrativa. In: BAUER, M. W. GASKELL, G. Pesquisa qualitativa com texto, imagem e som. Petrópolis: Vozes, 2002. p. 90-113.

LOURO, G. L. A história (oral) da educação: algumas reflexões. Brasília: INEP/MEC; Em Alberto, 1991.

MARKOVÁ, I. Mente dialógica: senso comum e ética. São Paulo: Fundação Carlos Chagas, 2017. 
MENDONÇA, R. F. Dimensão intersubjetiva da autorrealização: em defesa da teoria do reconhecimento. Revista Brasileira de Ciências Sociais, v. 24, n. 70, p. 143-154, 2009.

MOSCOVICI, S. A representação social da psicanálise. Rio de Janeiro: Zahar, 1978.

MOSCOVICI, S. Representações sociais: investigações em psicologia social. Rio de Janeiro: Vozes, 2015.

PASSEGGI, M. C. Narrar é humano! Autobiografar é um processo civilizatório. In: PASSEGGI, M. C.; SILVA, V. B. (org.). Invenções de vida, compreensão de itinerários e alternativas de formação. São Paulo: Cultura Acadêmica, 2010. p. 103-130.

PASSEGGI, M. C. A experiência em formação. Educação, Porto Alegre, v. 34, n. 2, p. 147-156, maio/ago. 2011.

PASSEGGI, M. C. Narrativa, experiência y reflexión autobiográfica: por una epistemologia del Sur en educación. In: ARANGO, G. J. M. (comp.). Narrativas de experiencia en educacióny pedagogia de la memoria. Buenos Aires: Editorial FFyL/UBA, 2015. p. 69-87.

PASSEGGI, M. C.; SOUZA, E. C. O movimento (auto)biográfico no Brasil. Investigación Cualitativa, v. 2, n. 1, p. 6-26, 2016.

PASSEGGI, M. C.; SOUZA, E. C.; VICENTINI, P. P. Entre a vida e a formação: pesquisa (auto)biográfica, docência e profissionalização. Educação em Revista, Belo Horizonte, v. 27, n. 1, p. 369-386, abr. 2011.

PEREIRA, L. M. L. Algumas reflexões sobre histórias de vida, biografias e autobiografias. História Oral, n. 3, p. 117-127, 2000.

PINEAU, G. As histórias de vida em formação: gênese de uma corrente de pesquisa açãoformação existencial. Educação e Pesquisa, v. 32, n. 2, p. 329-346, maio/ago. 2006.

QUEIROZ, M. I. P. Relatos orais: do “indizível” ao "dizível”. In: SIMSON, O. M. (org.). Experimentos com histórias de vida (Itália-Brasil). São Paulo: Vértice, 1988.

RIGOTTO, R. M. As técnicas de relatos orais e o estudo das representações sociais em Saúde. Ciência e Saúde Coletiva, v. 3, n. 1, p. 116-130, 1998.

SÃO PAULO (Estado). Secretaria da Educação. Resolução SE 68/2017. Dispõe sobre o atendimento educacional aos alunos da educação Especial. Disponível em: http://siau.edunet.sp.gov.br/ItemLise/arquivos/68_17.HTM?Time=17/02/2020\%2017:5 1:44. Acesso em: 17 fev. 2020.

SASSAKI, R. K. Inclusão. Construindo uma sociedade para todos. Rio de Janeiro: WVA, 1999.

SCHMIDT, B. B. O gênero biográfico no campo do conhecimento histórico: trajetória, tendências e impasses atuais e uma proposta de investigação. Anos 90, Porto Alegre, n. 6. p. 165-192, dez. 1996.

SCHUTZ, A. Le chercheur et le quotidien. Paris: Méridien Klincksieck, 1987. 
STEBAN, M. P. S. Pesquisa qualitativa em educação: fundamentos e tradições. Porto Alegre: Artmed, 2010.

WELLER, W. Grupos de discussão na pesquisa com adolescentes e jovens: aportes teóricos-metodológicos e análise de uma experiência com o método. Educação e Pesquisa, São Paulo, v. 32, n. 2, p. 241-260, maio/ago. 2006.

RECEBIDO: 01/06/2020 APROVADO: 28/07/2020

RECEIVED: 06/01/2020 APPROVED: 07/28/2020

RECIBIDO: 01/06/2020 APROBADO: $28 / 07 / 2020$ 